\section{REFERENCES}

Birnbaum, S. G., Varga, A. W., Yuan, L. L., Anderson, A. E., Sweatt, J.D., and Schrader, L. A. (2004). Structure and function of Kv4-family transient potassium channels. Physiol. Rev. 84, 803-833.

Clark, B. D., Kwon, E., Maffie, J., Jeong, H. Y., Nadal, M., Strop, P., and Rudy, B. (2008). DPP6 localization in brain supports function as a Kv4 channel associated protein. Front. Mol. Neurosci. 1, 8 .

Hoffman, D. A., Magee, J. C., Colbert, C. M., and Johnston, D. (1997). $\mathrm{K}^{+}$channel regulation of signal propagation in dendrites of hippocampal pyramidal neurons. Nature 387, 869-875.
Maffie, J., and Rudy, B. (2008). Weighing the evidence for a ternary protein complex mediating A-type $\mathrm{K}^{+}$currents in neurons. J. Physiol. 586, 5609-5623.

Nadal, M. S., Ozaita, A., Amarillo, Y., Vega-Saenz de Miera, E., Ma, Y., Mo, W., Goldberg, E. M., Misumi, Y., Ikehara, Y., Neubert, T. A., and Rudy, B. (2003). The CD26-related dipeptidyl aminopeptidase-like protein DPPX is a critical component of neuronal A-type $\mathrm{K}^{+}$channels. Neuron 37, 449-461.

Strop, P., Bankovich, A. J., Hansen, K. C., Garcia, K. C., and Brunger, A. T. (2004). Structure of a human
A-type potassium channel interacting protein DPPX, a member of the dipeptidyl aminopeptidase family. J. Mol. Biol. 343, 1055-1065.

Received: 30 April 2009; published: 15 September 2009. Citation: Front. Neurosci. (2009) 3, 2: 158-159. doi: 10.3389/neuro.01.017.2009

Copyright $\odot 2009$ Attali. This is an open-access publication subject to an exclusive license agreement between the authors and the Frontiers Research Foundation, which permits unrestricted use, distribution, and reproduction in any medium, provided the original authors and source are credited.

\title{
Details of the construction of perception: a closer look at illusory contours
}

\author{
Johan Eriksson* and Lars Nyberg** \\ Physiology Section, Department of Integrative Medical Biology, Umeå University, Umeå, Sweden \\ *Correspondence: *johan.eriksson@physiol.umu.se; **lars.nyberg@physiol.umu.se
}

\section{A commentary on}

Retinotopic activation in response to subjective contours in primary visual cortex

by Marianne Maertens, Stefan Pollmann, Michael Hanke, Toralf Mildner and Harald Möller

Are we aware of neural activity in primary visual cortex? This question was asked in a classic paper written by Nobel laureate Francis Crick and Christof Koch more than a decade ago (Crick and Koch, 1995). By now, several studies have addressed the question, but so far consensus has not been reached (Rees, 2007; Tong, 2003). A recent study by Maertens et al. (2008) presents new relevant data on this issue. They demonstrated that activity in primary visual cortex (V1) is correlated with the perception of subjective contours. Maertens et al. used Kanizsa figures to induce a percept of illusory contours (IC, Figure 1), which are subjective in the sense that there is no actual change in luminance at the location of the perceived contour.

The (illusory) perception of the contours is dependent on coherent orientation of the inducers. Hence, by either aligning or misaligning the inducers, very similar

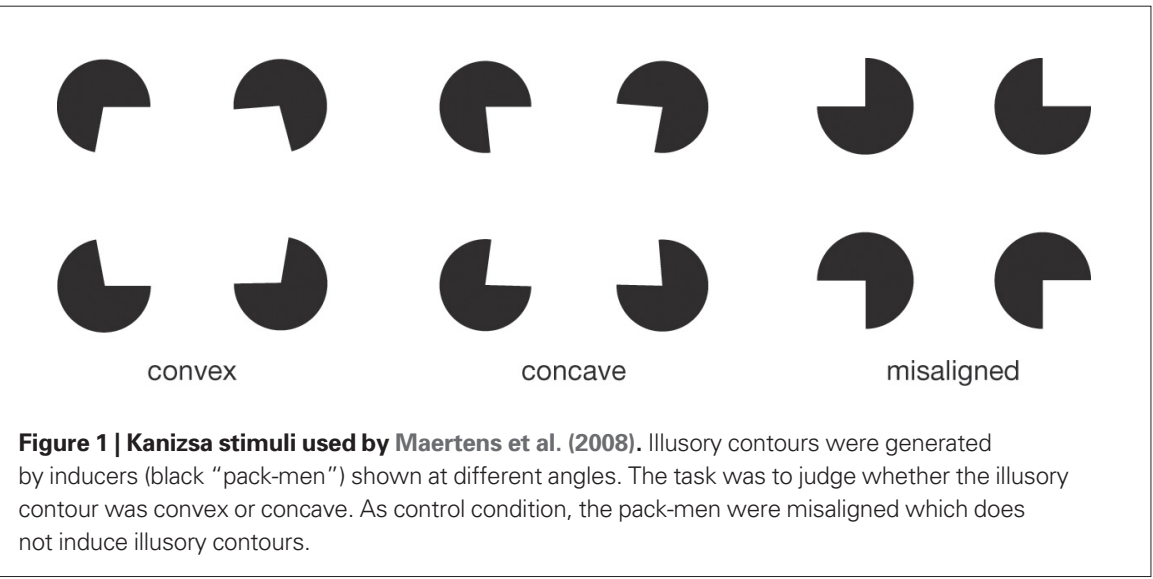

(local) physical parameters can create two subjectively different visual experiences. IC can therefore be used to provide information on neural correlates of conscious perception.

An important feature of Maertens et al.'s experiment was the localization of neural activity specific for contour perception. This was accomplished by using spatially specific localizer stimuli for the contours and inducers separately, as well as by using a spatially more precise imaging sequence than traditionally used ones. This enabled the conclusion that the IC were related to retinotopically specific regions within $\mathrm{V} 1$, thereby extending previous research on IC where IC-related activity at such a level of detail was not observed. The results also add to existing evidence regarding $\mathrm{V} 1$ involvement in conscious perception. In previous research on conscious perception, some but not other studies have observed correlated activity in V1. A factor that could account for the inconsistent results is the specific task requirements. Specifically, it has been suggested that there is a reverse hierarchical sequence for conscious perception such that global, holistic features are perceived first and the details are added if required (Hochstein and Ahissar, 2002). In the Maertens et al. paper, the angle of the 
induced contrasts was varied between trials and the participant was required to judge the angle on each trial (Figure 1). Hence, the task mandated a fine-scaled decision which required detail to be extracted detail at such a fine scale that it may only be present in V1 due to its small receptive fields - and might therefore have induced correlated V1 activity.

A hypothesis put forth by Crick and Koch in their 1995 paper was that, while activity in V1 may be necessary for conscious perception, it may not be sufficient. According to Crick and Koch, sensory regions need to be connected to prefrontal cortex to enable conscious perception. Whether involvement of frontal regions is necessary remains controversial (Eriksson et al.,2008), but a role of prefrontal cortex is indicated by a large number of neuroimaging studies showing a correlation between activity in frontal regions and conscious perception (Naghavi and Nyberg, 2005; Rees et al., 2002). In the Maertens et al. study, a limited part of the brain was sampled to improve spatial resolution. While this enabled the retinotopic mapping of the IC and thus constituted a great strength of study, this level of detail comes with a cost as nothing could be concluded regarding frontal involvement in the creation of IC. Future work, building on the methods used in the Maertens et al. study along with whole-brain sampling could shed light on the involvement of higher-order cortical regions and necessary vs. sufficient conditions for conscious perception.

In sum, the Maertens et al. study is an excellent demonstration of the constructive nature of perception (Helmholtz, 1910). Moreover, it shows that this constructive process is not confined to higher levels of the visual hierarchy, but can take place even at the lowest level of cortical processing.

\section{REFERENCES}

Crick, F., and Koch, C. (1995). Are we aware of neural activity in primary visual cortex? Nature 375, 121-123.

Eriksson, J., Larsson, A., and Nyberg, L. (2008). Item-specific training reduces prefrontal cortical involvement in perceptual awareness. J. Cogn. Neurosci. 20, 1777-1787.
Hochstein, S., and Ahissar, M. (2002). View from the top: hierarchies and reverse hierarchies in the visual system. Neuron 36, 791-804.

Maertens, M., Pollmann, S., Hanke, M., Mildner, T., and Möller, H. E. (2008). Retinotopic activation in response to subjective contours in primary visual cortex. Front. Hum. Neurosci. 2. doi: 10.3389/ neuro.09.002.2008. [Epub ahead of print].

Naghavi, H. R., and Nyberg, L. (2005). Common fronto-parietal activity in attention, memory, and consciousness: shared demands on integration? Conscious. Cogn. 14, 390-425.

Rees, G. (2007). Neural correlates of the contents of visual awareness in humans. Philos. Trans. R. Soc. Lond., B, Biol. Sci. 362, 877-886.

Rees, G., Kreiman, G., and Koch, C. (2002). Neural correlates of consciousness in humans. Nat. Rev. Neurosci. 3, 261-270.

Tong, F. (2003). Primary visual cortex and visual awareness. Nat. Rev. Neurosci. 4, 219-229.

von Helmholtz, H. (1910). Handbuch der physiologischen optik, Vol. 3, $3^{\text {rd }}$ Edn. Leipzig, Leopold Voss.

Received: 28 April 2009; published: 15 September 2009. Citation: Front. Neurosci. (2009) 3, 2: 159-160. doi: 10.3389/neuro.01.018.2009

Copyright (c) 2009 Eriksson and Nyberg. This is an openaccess publication subject to an exclusive license agreement between the authors and the Frontiers Research Foundation, which permits unrestricted use, distribution, and reproduction in any medium, provided the original authors and source are credited.

\section{Calcium waves in astrocyte networks: theory and experiments}

\section{Michele Giugliano ${ }^{1,2 *}$}

1 Department of Biomedical Sciences, University of Antwerp, Wilrijk, Belgium

2 Laboratory of Neural Microcircuitry, Brain Mind Institute, EPFL, Lausanne, Switzerland

*Correspondence: michele.giugliano@ua.ac.be

\section{A commentary on}

Diffusion modeling of ATP signaling suggests a partially regenerative mechanism underlies astrocyte intercellular calcium waves

by Christopher L. MacDonald, Diana Yu, Marius Buibas and Gabriel A. Silva

In the central nervous system (CNS), astrocytes participate in supportive functions, such as metabolism, ion homeostasis, neurotransmitter recycling and tissue integrityrestoration. However, astrocytes are also deeply involved in a variety of complex phe- nomena, including CNS physiology, information processing, and synaptic plasticity (Fellin, 2009). These make the investigation of astrocytes (dis)functions as challenging as of neurons and synapses.

Interestingly, astrocytes are excitable cells like neurons. They base their communication on spontaneous or evoked cytosolic $\mathrm{Ca}^{2+}$ variations, instead of membrane electrical transients. Their remarkable morphology supports intercellular signaling as they form interconnected networks of cells coupled by gap-junctions, where each unit occupies a virtually non-overlapping domain of the inter-neuronal space. Surprisingly, astrocytes communicate also to neurons and synapses. In fact, they extend membrane processes to simultaneously contact hundreds of neuronal dendrites, thousands of synapses and even blood vessels. Indeed, astrocytes control the vasculature tone and they are likely to sense neuronal energydemand and gate its consumption. Their physiology is thus bidirectionally linked to neuronal and synaptic activity, as they are capable of selectively respond to it on a millisecond time scale, by releasing specific neuroactive molecules (Ni et al., 2007). Notable are the discoveries of the interaction with synaptic physiology and plasticity that led 